\title{
Investigation the effects of comparison between bilingual instruction and the use of L2
}

\author{
Fatemeh Mirzaei*1, Muhammad Ridhuan Tony Lim Bin Abdullah², Zulqarnain B Abu Bakar², Waseem Sattar ${ }^{4}$
}

${ }^{1}$ Management and Humanities Department, Universiti Teknologi PETRONAS, Perak, Malaysia

${ }^{2}$ Management and Humanities Department, Universiti Teknologi PETRONAS, Perak, Malaysia

${ }^{3}$ Management and Humanities Department, Universiti Teknologi PETRONAS, Perak, Malaysia

${ }^{4}$ Management and Humanities Department, Universiti Teknologi PETRONAS, Perak, Malaysia

\begin{abstract}
This paper is a comparison of the impact of using bilingual instruction and the use of L2 on learners' learning improvement. The mixed mode is used to determine the use of mother language (L1) as a resource helped the students in learning. The respondents were selected from faculty of Management in UTM, Malaysia. They used rarely English language outside of the school and had average level of English language proficiency. In this paper, it also distinguished resource, difficulties and challenges which the students faced in using bilingual instruction. The questionnaire was used to determine students' perceptions and data was analyzed by SPSS. In addition, the data was collected from interview which is transcribed and described. The results indicated that L1 in UTM can be used as a resource to teach specific subjects to students. According to the results, respondents had positive attitudes about using bilingual instruction in the class and it was effective on students' leaning improvement. Based on findings, it is hoped that positive feedback in this research provide a reason why L1 should be used in teaching and look it as a resource for language learning in the future.
\end{abstract}

\section{Introduction}

The use of first language (L1) is an important issue in learning language. There are different views on using L1 in teaching foreign/second language. A number of researchers argue that using L1 can be beneficial to learn foreign language and some disagree. Monolingual's advocates believe that learning foreign/second language should be used in the classroom (Jadallah and Hasan, 2009). Jones (2010) found out that beyond the L2 input essential role in learning second language, the use of the L1 can help the learners to learn L2 better. He mentioned that the teachers are struggling between theory and practicality. According to theory the teacher cannot use L1, in contrast they experienced that using L1 can be valuable tool in function of the L2 and help learners to feel secure.

There are many different viewpoints and arguments in using L1 and L2 coincidently in teaching and learning L2. This study will discuss about those arguments in following sections and will conclude that whether the use of L1 cab helpful in learning ESP beyond learning L2.

\section{Literature Review}

Most of the applied linguistics, linguistics and psychologists approve the influence of using L1 in second language acquisition. Despite that some agree to use L1 in learning L2 and others believes using L1 can be as hindrance to L2 learning.

*Corresponding author: fatemeh_16005850@utp.edu.my 
These different views on the role of the L1 are considered in the concept of language transfer (Faerch and Kasper, 1987). They define it as the process when the students use L1 knowledge in improving or the use of interlanguage.. They also note that that process can be positive or negative transfer.In accordance with Ellis (1984) many researchers support using English only in teaching. They believe that using L1is not necessary and also using of it too much cause to prevent appropriate input of L2. With regard to views are mentioned above, advocates of using L1 think that the use of L1 can provide students t to understand better and promote their skills. They believe that it can work as strategy to make students understand comprehensibly (Jadallah and Hasan ,2009)

The reason why some researchers oppose to the use of L1 is related to the Grammar Translation Method (GTM). This method focuses on structure, vocabulary and understanding literature. The rules are very important in GTM and the teachers teach deductively (Chastain, 1988). Harmer (2001) states Students' disability to communicate cause that many researchers concluded that learning target language is boring and without communicative point. Later on, Audiolingual Method and Direct Method avoid using L1 in teaching English language (Jadallah and Hasan, 2009).

\subsection{Code Switching}

The above two different views discussed on the role of the L1 has influenced teachers' views as to whether the students should use L1 in language classroom. The other phenomenon that is also draws attention due to its reliance on L1 knowing is code mixing and code switching. Code mixing can be defined as situation in which a word or an expression from is language is used in a group of words whose structure belongs to another language. Code switching is when learners use complete sentences from both languages.

Code mixing is a widespread phenomenon in bilingual communities where speakers use their native language (L1) and their second language (L2) in certain different domains (Celik, 2003). One strong view against the practice of code switching in the classroom is expressed by Wong-Filmore (1985). She has questioned the use of L1 in the language classroom. In her three years longitudinal study investigating language learning process, proficiency and acquisition. She concluded that teachers who switched to the L1 were a practice in unsuccessful classroom but never in successful ones. She states the use of the L1 did not aid students in their efforts to learn a new language.

On the other hand, Cook $(2001,2003)$ is today's leading and influential voice advocating ode switching. He argues that language teachers should break away from the long held tradition that marginalized the use of L1. Proponents of code switching believe that the L1 plays a cognitive role in helping students comprehend and achieve language tasks (Anton and Dilamilla, 1999 cited in Cook, 2001). They also view L1 as a mediating tool when learner works collaborating and cognitively effective strategy to develop language learning. Viakinna-Brinson (2006) study provided insights on the use of code switching as students liked being taught grammar in French/ English ... as it was easier to understand the smaller technical details students with insufficient vocabulary will benefit from such learning and progress foster in language acquisition. The L1 'role as resource and language learning facilitators is imminent besides being a strategy for learners to overcome their limitations in second language acquisition (Ellis, 1985).

In Malaysia English as a second language is used more than using in work places such as in education. Education ministry of Malaysia insists to teach English language in schools. Teachers have to use English language only in the classroom perfectly (Ahmad, H, 2009).

Based on Ahmad,H (2009) Malaysian students' low proficiency level in English language cause the teachers solve this problem. Teachers have concluded that code switching can help them as a tool to provide students to be self-confident in communicating in English. In addition, code switching provides students to understand better. It helps to time saving that it is important issue in teaching. Teachers can use it to clarify difficult points in English language instead of explaining that takes much time. Norrish (1997, cited in Ahmad,H, 2009) claims that teachers use code switching when the levels of the students are low and they tire out to adapt themselves to their levels. 


\subsection{Arguments on the Use of Bilingual Instruction}

The role of the L1 either as a resource or as a hindrance have reviewed in previous sections. In this section, it aims to review the literature of bilingual instruction in second language learning classroom. The L2 have a large amount of knowledge when participate in L2 classroom and want to relate it to L2. Besides, they know the general knowledge and communicating strategy that help them to understand L2 input better (Ellis, 1997). Sapada and Lightbown (1999) considered the awareness of the differences between L1 and L2 can help learners to face difficulties in L2 learning. In addition, Huang (2007) claims that both linguistic students and teachers support the significant role of the L1 in L2 learning. The logical factor behind using English language only in ESL and EFL classroom is "neither conclusive nor pedagogically sound" (Auerbach, 1993). Maarof (2003) pointed out" teachers can reassure the judicious use of the L1 in ESL classroom is acceptable pedagogically and theoretically and can be efficiently utilized to assist students learning L2. Using bilingual instruction during"

In the following sections, the influence of bilingual instruction will be reviewed in two perspectives in second language learning. The role of the bilingual instruction in comprehension and visualization in learning language for specific purposes.

\subsection{Bilingual and Language Awareness}

Another argument for bilingual instruction comes from the development in the area of language awareness. There have been difficulty views on how grammar is acquire and how best to teach grammar. Chomsky (1979) theorizes that we do not "really learn the language rather the grammar grows in the mind". Then again, there is, however very little clear evidence in support of the claim that practice makes perfect or that structures can be taught (Ellis, 1988) Carder (1967), viewed that language teacher' primary function should be to facilitate the unfolding of what he recognized as the learner' powerful internal syllabus, not to try to impose an external one (cited in Fakharzadeh, 2009). As students become aware of the target language, they start noticing as noticing is related to the question of what is started in memory (Schmit,1993 cited in McGinnis, 2007). Learners may consider both target language and their own language from their own views (Swain, 1998).

Inability to produce the target language will reveal to the learners the 'hole' in one's interlanguage. Thus the learner will then push the limits of the interlanguage system to handle the output by comparing it with the internalized knowledge, the L1 rules. Noticing draws attention to the similarities and differences in form, for both the L1 and L2. Auerbach (1993) insists that the L1 should be used to complement the L2 learning process and to later 'generate attention to L2 production'. This claim is also supported by Jiang and Kuehen's (2001) study findings on transfer in academic language development amongst low-intermediate ESL students. 62 percent of students in the older group said they thought about their L1 grammar when learning English grammar. In summation, since students refer back to their L1 knowledge to learn the same domains of knowledge in L2 to facilitate learning, using bilingual instructions in an ESL classroom will raise consciousness as students start noticing the L2 form and become aware of its language structures.

\subsection{Bilingual and Comprehension}

The use of L1 does not mean to use L1 to teach L2. Using L1 provides teachers to explain the difficult points of grammar and make clear the comparison between L1 and L2 equivalent (Jadalla and Hasan,2009). Atkinson states three reason why the use of L1 can be useful in EFL classroom: using L1 cause students to feel secure, different features of L1 and L2 prevent negative transfer and it can be useful in timesaving. He adds that the use of L1 help teachers to correct the comprehension of students and encourage them to cooperate in discussion in the classroom. Furthermore, develop and reinforce the presentation of the students. Harbord (1992 cited in Jadalla and Hassan, 2009) completes Atkinson' reasons. He states that L1 encourage students to participate in task of English language learning. Using L1 is also beneficial to teachers. He claims the teachers can chat with students, correct their errors, explain instruction and clarify the comprehension (Sharma, 2006). 
Jiang and Keuhen (2001) advocate using bilingual instruction because it allows positive transfer of skills. They note that the teachers can teach students the ways that students use L2 effectively whether the teacher emphasizes on positive transfer. As a result, in a bilingual environment besides mentioned reasons for using L1, teachers and students can share their similar linguistic and cultural background. "It would be compatible with the general educational principle that learning involves developing new knowledge based on what is familiar" (Seidhofer, 2004. Cook, 2001).

\section{Research design}

Both quantitative and qualitative data are collected. This study will investigate how bilingual instruction affects students' learning of the specific subjects that are taught in English. It will also distinguish resources, difficulties and challenges the students faced in using bilingual instruction. Data are collected and analysed based on qualitative and quantitative method to explain the perception of using bilingual instruction and its resources and difficulties among management and human resource undergraduate students in UTM. The questionnaire (Maleki, 2005) includes two demography and perceptual sections are distributed among undergraduate students of Management and Human Resources Faculty at UTM. Then the data is analysed by SPSS. The interview data will be transcribed and described. For observing class, filled transcription and description will be used. Two sets of the specialist texts are provided to investigate the comprehension of students and then those texts are described. Data was collected through written survey questionnaire and semi-structured interviews with the participants. The use of these two data collection instruments help validate both the answers in the questionnaire and interviews.

\section{Discussion on Research Question 1:}

What are the perceptions of students towards using bilingual instruction?

To answer the first research question in this study, survey questionnaires were distributed among undergraduate students of Management and Human Resource Faculty. The aim of the questionnaire was to determine the students' perception toward using bilingual instruction and also to prove the first hypothesis that undergraduate students have positive attitudes toward using bilingual instruction in learning specific subjects.

According to the results of previous section, it is shown that most of the respondents agree with the use of bilingual instruction by lecturer to explain specific vocabularies (Item 2), explain concept of the subject (Item 3), and check the students' comprehension (Item 4). These findings are similar to the results of Ahmad's (2009) research when he discovered that university students had positive attitudes on using code switching in classroom which helps them to feel comfortable in the classroom.

But based on responses of interviewees who preferred the lecturers to use English language which are similar to the results reported by Ndamba (2008). In his research which examined the students and their parents' preferences of using mother tongue or English language in Zimbabwe, he found out that the respondents preferred English use in the classroom. His research respondents defined English language as 'Gateway' which is more close to answers of interviewees in this study. Interviewees in this research mentioned that they preferred to use English language in classroom because it is international language and proficiency in it helps them to find better job in the future.

Regarding to the results of presented study, it was found that the majority of respondents are neutral about using bilingual instruction to give instruction and on the other hand, Table 6 shows that the moderate number of respondents are neutral about presenting subject in bilingual instruction too. It might show that it is not important to them that lecturer' use of bilingual instruction to present subject or give instructions. It might indicate that they do not pay attention to language usage in the classroom. In addition, according to interview all of them said that they understand comprehensibly when the lecturer uses bilingual instruction in presenting and checking their comprehension. They emphasized that in answering the questions in examination, using bilingual instruction help them to understand the concept of test instructions and answer the questions confidently.

Totally, based on findings students agree that lecturers should use bilingual instruction in the classroom. On the other hand, it is needed to know the lecturers' perceptions on using bilingual instruction. A study done by Ford (2009) who carried out a research on teachers' perceptions in EFL context in Japan. He discovered that most of teachers tended to use English language but they mentioned that it depends on students' level and motivation. Teachers in her research stated that sometimes it is needed to use first language to provide relaxed atmosphere. It supported the results of this study which discovered that students preferred to use first language. Using Bahasa Malaysia help them to feel secure and comfortable which is more important point in learning improvement that will be discussed in next section. 
According to the results students' use of bilingual instruction, it was found that the majority of respondents 'Agree' with using bilingual instruction. They agree that they should be allowed to use bilingual instruction. More than fifty percent 'Agree' that using bilingual instruction encourage students to be active in the classroom. On the other hand, it was found that the percentages of respondents are almost close together to answer the question 10 which referred to the use of bilingual instruction in class discussion. But it is clear that the percentage of agreement with the use of bilingual instruction is more than disagreement. It shows that the majority of the respondents 'Agree' to use bilingual instruction in class discussion because they can be active and comfortable._

It is supported by Ahmad's (2009) results; he found that there is significant relation between students' participation and using L1. He reported the students are more active and feel comfortable to participate in class discussion when they are permitted to use L1. In addition, Zabrodskaj (2007) investigated the Russian speaking learners' experiences during learning Estonian as foreign language in linguistic course. He discovered that code switching as mentioned in Literature Review of this study is learning facilitator beyond a strategy. He found out that using L1 helps learners to feel comfortable in their presenting in seminars which can be very useful in speaking skills.

Finally, by looking at the results of questionnaires and interview according the first question, the respondents from Faculty of Management and Human Resource's students surveyed lies in their perceptions and view on using bilingual instruction. Most of the respondents viewed English as a must in their field of study. It should be mentioned that most of the respondents from all groups (Management, Human Resource and Marketing) either 'strongly agree' and 'agree' that using Bahasa Malaysia is helpful but equally the respondents believe that there is a need in their classroom to take further attention to English language. The interviewees mentioned that English language as language of their textbooks must be used in the classroom to increase their proficiency in English language for getting job in the future.

\subsection{Discussion on Research Question No 2:}

How does the use of bilingual instruction promote students' learning of specific subject in English?

Most of the respondents of all groups agree the use of Bahasa Malaysia affect their learning and help them to comprehend the subject in the classroom. They 'Agree' that the English language should be accepted officially academically in UTM to conduct courses but on the other hand the lecturers use Bahasa Malaysia to teach comprehensibly. They were also in favor of having bilingual instruction that promote the use of English in UTM. It is supported by results of Fakharzadeh' (2009) research which proved that using first language or the use of translation in presenting lecture promotes the students' learning. And also, she stated "it can be used as a technique for raising consciousness at different linguistic and discourse.

Levels, including grammar, lexis, rhetoric and genre". As it was found in this study, students "Agree' that using bilingual instruction either in lecturer' presentation or in test instructions are clearer than using English only. Fakharzadeh' (2009) also noted that using first language in teaching motivate students and improve the students' autonomy. The students have self confidence in the classroom that it was found in presented research. The most of the respondents 'Agree' that using bilingual instruction give good feeling in the classroom and are self-confident to participate and be active in class discussion.

It should be mentioned that, there were close percentages between 'Agree' and 'Neutral' option among responses. It shows that the using of bilingual instruction for the moderate of respondents is not as a great matter in learning or comprehension of subject. It may show that using English language is not a challenge for these respondents because it is as a second language in Malaysia and they use it daily. But according to Ahmad (2009), low proficiency level of English language causes teachers to use Bahasa Malaysia though their teaching to explain the concept of subjects. Based on reported interview, two of three of participants agree that using Bahasa Malaysia can be helpful in concept understanding and answer in questions of examinations. But, it was found that it can be related to subjects or grade level of students. Because, based on responses of interviewees, except two or three general or compulsory subjects which are taught in Bahasa Malaysia another one are taught in English. They all agree that presenting in English is more useful than using Bahasa Malaysia because their books are in English. They mentioned that some 'English Terms' are not same in Bahasa Malaysia. In addition, according to interview discussion, the respondents agree that using English language help them to able to use English language and get self-confidence to get job. They believe that English language proficiency as a skill improve their communication and help them to find a good job in the future. And also, they added that using Bahasa Malaysia in brainstorming help more to understand the main concept of the subject. 
One of the interviewees emphasized that English language as worldwide language must be used in the classroom especially for specific purposes. He believed that using English language help him to find a good job. He added that bilingual instruction also can help them to comprehend better but it should not be as first option to teach. He noted that using Bahasa Malaysia can be useful for weak students and impress them not to be passive in the classroom. On the other hand, one of them emphasized that because of the English language as original language in textbooks and specific words and terms, they cannot use Bahasa Malaysia most of the time. But using it to make clear the concept of the subject.

As Ndamba (2008) found out in his research most of the respondents (students, their parents and teachers) agree to use only English in learning foreign language. He mentioned that it is great concern for Education Ministry that mother tongue (L1) is ignored in language learning. It may concern in ESL context in UTM and it should be considered specifically.

\section{Conclusion}

The results of the study firstly indicate that the mother tongue (Bahasa Malaysia) can be used as a resource for teaching specific subject especially among ESP students. With the use of bilingual instruction students feel comfortable to comprehend the subjects and answer the questions of examinations confidently. They can focus on concept of subjects without being worry about level of English language proficiency. Although, most of them generally know English language because English is as second language in Malaysia and the people use English as daily language.

Secondly, the results of this study strongly confirmed the second hypothesis based upon using bilingual instruction influences students' learning significantly. According to responses of interview and questionnaires, it was discovered that with the use of bilingual instruction the students focus on concepts of subjects and reduce their stress during learning process. Interviewees agree that using bilingual instruction help weak students to improve in learning English beyond learning their subjects. Also, the use of L1 influences the interlanguage development and helps the students' language ability to improve in the target language learning much quicker. The use of L1 as a resource in ESL context may be a workable method especially for ESP learners which teachers should investigate on.

\section{Implication of the Study}

The results of this research showed that the majority of respondents surveyed indicated they had positive view on using bilingual instruction in the classroom. Most of the respondents agree that using bilingual instruction help and facilitate learning process. The faculties involved should consider coming up with syllabus based on the English for the Specific Purpose (ESP) approach to teaching the Marketing, Management and Human Resource. As the underlying aspects of this approach is based on the consideration of students' needs and a high motivational level to learn, the results of this study showed both elements were presented in the faculty of Management and Human Resource. It was mentioned in chapter two that the learner or student is center of ESP learning. It can be concluded that learners' needs should be considered as main part for teaching specific subjects that they prefer to use L1 and English language concurrently.

\section{Recommendations}

This research proceeded on students' perception which is as small scale in bilingual instruction. It is highly recommended that firstly using L1 should be taken to account to L1(Bahasa Malaysia) more in presenting lectures which improves students learning, based on findings of this study using L1 as resource help students to be comfortable and feel secure which is useful in learning. Next, future research can see the concept of subject clearly should be thinking aloud in L1. It shows that it. Thirdly, results in this research showed that how using Bahasa Malaysia influences learning improvement so, it can be recommended that technical Malay Standard Bahasa Malaysia should be taught in L1. Then, the number of subjects or sample of the study need to be increased to at least thirty percent of the entire intended population in order to get more findings. Finally, the relation between bilingual instruction with other factors such as awareness, imagination which can be more influenced in learning.

This work was funded by the YUTP grant cost centre no. 0153AA-E59. The authors would like to thank the reviewers for their valuable comments to improve this paper. 


\section{References}

Ahmad, H. (2009). Teacher's Code Switching in classroom Instruction for Low English Proficient Learners. 2, (2).

Atkinson, D. (1987) The mother tongue in the classroom: a neglected resource?, ELT Journal, 41(4): 241-247.

Auerbach, E. R. (1993). Reexamining English only in the ELT classroom. TESOL Quarterly, 27(1), 29-32

Chastain, K. (1988). Developing Second Language Skills. Harcourt Brace Jovanovich. Inc.

Chomsky, N. (1979). Language and responsibility. New York: St Martin's Press.

Celik, M. (2003). Teaching Vocabulary Through Code- mixing ELT Journal, (57) 4: 361-369, October 2003. https://doi.org/10.1093/elt/57.4.361

Cook, V. J. (2001) Using the first language in the classroom. Carddian Modern Language Review, 57: 402-423.

Cook, V. J. (2003). Effects of the Second Language On the First. Tawnawanda, NY: Multilingual Matters Ltd.

Ellis, R. (1997). Second Language Acquisition. Oxford: oxford University Press.

Ellis, R. (1988). The role of practice in classroom language: learning Teanga 8: 1-28

Ellis, R. (1985). Understanding Second Language Acquisition. Oxford: Oxford University Press.

Ellis, R. (1984). Second Language Acquisition and Language Pedagogy Clevedon: Mulitilingual Matters.

Faerch, C. and Kasper, G. (1987). Introspection in Second Language Research Clevelind, OH: Multilingual Matters Ltd.

Fakharzadeh, M. (2009). Why's of Pro-First Language Use Arguments in ESP Context. PhD University of Isfahan, Iran.

Ford, K. (2009). Principles and Practices of L1/L2 Use in the Japanese University EFL Classroom. JALT Journal, 31 (1).

Harmer, J. (1991). The practice of English Language Teaching. London: Longman.

Huang, L. (2007). Strategies in ELL Literacy Development: effective Strategies for Teachers in english Language Learners' Literacy Development. Master's Thesis. South Minnesota State University. Minnesota.

Jadallah, M. and Hasan, F. (2009). A Review of Some New Trends in Using L1 in the EFL Classroom. Al-Quds Open University.

Jiang, B. and Kuehen, P. (2001). Transfer in the academic language development of post-secondary ESL students. Bilingual Research Journal. 25(4).

Jones, H. (2010). First Language Communication in the Second Language Classroom: A Valuable or Damaging Resource? Education 6390 Memorial University of Newfoundland.

Lightbown, P. and Spada, N. (1999). How Language are Learnt. Oxford: oxford University Press.

Maarof, M. (2003). University the Native Language or L1 to comprehend L2 texts. In International Conference on Language and Nationhood. Putrajaya: Intensive of Malaysian and International studies, UKM.

Maleki, A. (2005). ESP Teaching: A Matter of Controversy. Preceedings of the First National ESP/EAP Conference (vol. 1). SAMT, Tehran, PP.169-178.

Ndamba, G. T. (2008). Mother Tongue Usage in Learning: An Examination of Language Preferences in Zimbabwe. The Journal of Pan African Studies, 2 (4). 
Norrish, J. (1997). English or english? Attitudes local varieties and English language teaching. In TESL_E (3) 1. Retrieved September 5. 2005, www. Writing. Berkerley. Edu/ TESL-EL/ ej09/ a2. Html.

Sharma, D. (2006). The Art of Communication. The Journal of English Language Teaching (India), XLIV/5, 41-43.

Seidlhofer, A. B. (2004), 'Research perspectives on teaching English as a lingua franca', Annual Review of Applied Linguistics, 24, 209-239.

Sapada. N and P. M. Lightbown, (1999). Instruction and the development of questions in L2 classrooms. Studies in Second Language Acquisition. 15, 2015-24.

Swain, M. (1998). From on Form through Concouis Reflecyion. In C. Doughty and J. Williams (Eds). Focus on Form in Classroom Second Language Acquisition. New York: Cambridge University Press.

Viakinnour-Brinson, L. (2006). To Teach or Not To Teach IN The Target Language Only? The effect of target language only and code-switching on the Grammatical Performance of Elementary Level French Students. PhD thesis. Graduate School of Emory University.

Wong-Filmore, L. (1985), When Does Teacher Talk Was Input? In S.M.Gass and C.G, madden (Eds), Input in Second Language Acquisition. Rowley. MA: Newbeny.

Zabrodskaja A. (2007). "Russian-Estonian code-switching in the university”, SLA \& Teaching, Vol. 14, pp. 123-139. 